\title{
USO DO PROCESSAMENTO LARGAMENTE EM UM EQUALIZADOR FRACIONALMENTE ESPAÇADO APLICADO A CANAIS DE COMUNICAÇÕES SELETIVOS EM FREQUÊNCIA
}

\author{
F. J. A. AQUINO
}

Grupo de Processamento de Sinais - Instituto Federal do Ceará

fcoalves_aq @ifce.edu.br

Artigo submetido em dezembro/2011 e aceito em setembro/2012

\section{RESUMO}

Os sistemas de comunicação que usam o ar (espaço) como meio de transmissão de dados estão sujeitos aos problemas de falta de visada direta e interferências, sendo, quase sempre, necessário um filtro (equalizador) para compensar os efeitos indesejáveis introduzidos pelo canal de comunicação. Inicialmente, este artigo apresenta os conceitos básicos sobre comunicação digital. Em seguida, é realizada uma análise do uso do processamento largamente linear aplicado à equalização de canais de comunicação usando equalizadores fracionalmente espaçados (FE). Resultados de simulação mostram que esta abordagem pode resolver com eficiência o problema de equalização do canal de comunicação digital.

PALAVRAS-CHAVE: equalização, processamento largamente linear, canal de comunicação.

\section{USE OF WIDELY LINEAR PROCESSING IN A FRACTIONAL EQUALIZER APPLIED TO COMMUNICATION CHANNELS FREQUENCY SELECTIVE}

\section{ABSTRACT}

Communication systems that use air (space) as means of data transmission are subject to problems interference and lack of sight, being often, require a filter (equalizer) to offset the adverse effects introduced by the communication channel. Initially, this paper presents the basics of digital communication. Next is an analysis of the use of widely linear processing applied to the equalization of communication channels using fractionally spaced equalizer (FE). Simulation results show that this approach can effectively solve the problem of equalization of digital communication channel.

KEY-WORDS: equalization, widely linear processing, communication channel. 


\section{USO DO PROCESSAMENTO LARGAMENTE EM UM EQUALIZADOR FRACIONALMENTE ESPAÇADO APLICADO A CANAIS DE COMUNICAÇÕES SELETIVOS EM FREQUÊNCIA}

\section{INTRODUÇÃO}

Os sistemas de comunicações digitais, devido às altas taxas de dados requeridas e da limitação da banda passante do canal de comunicação, sofrem com o problema de interferência entre os símbolos (IES). O canal de comunicação, especialmente no caso das comunicações sem fio, pode introduzir uma distorção considerável no sinal transmitido, especialmente quando o sinal é propagado nas cidades onde se encontram muitas construções que servem de obstáculos à propagação dos dados, de tal forma que o receptor irá precisar de algum dispositivo capaz de mitigar os efeitos da distorção. Tal dispositivo é chamado de equalizador (Proakis, 1995; Pimentel, 2007). Pode-se definir o equalizador como sendo qualquer dispositivo ou algoritmo de processamento de sinal usado para reduzir a IES.

O uso de equalizadores adaptativos para compensar os efeitos do canal vem desde a década de 1960 com os trabalhos pioneiros de Widrow e Holf (1960), Lucky (1966), Saltzberg (1968) e Lugannani (1969). Posteriormente, muitas contribuições foram feitas a esses trabalhos pioneiros. Neste artigo são abordadas duas dessas contribuições e a combinação delas em um único equalizador.

Este artigo é organizado em nove seções. Na Seção 2 são apresentados os conceitos referentes a um sistema de comunicação digital. A Seção 3 mostra a notação matemática necessária para descrever tais sistemas. Em seguida, nas seções 4 e 5, são descritos os fundamentos do processamento largamente linear e a equalização adaptativa de canal. A Seção 6 aborda os equalizadores fracionalmente espaçados. Na Seção 7 é abordada a combinação dessas duas técnicas na equalização do canal de comunicação digital. Finalizando o artigo, na Seção 8, são apresentados os resultados de simulação e na Seção 9 são apresentadas as conclusões.

\section{SISTEMA DE COMUNICAÇÃO DIGITAL}

Os blocos básicos de um sistema de comunicação digital estão ilustrados na Figura 1. A seguir, esses blocos são detalhados de forma sucinta. Deve-se ter em mente que a função desse sistema é entregar ao usuário a informação gerada pela fonte da forma mais confiável possível e sem erros, mesmo tendo que passar por um canal hostil à comunicação de dados.

A fonte de informação pode produzir dados já no formato binário (saída de um computador) ou ser proveniente de um sistema analógico, como um sinal de voz. No caso de uma fonte analógica, a mensagem a ser transmitida deve ser inicialmente convertida em uma sequência de dígitos binários com o uso de um conversor analógico-digital.

Em geral, um sinal de voz ou uma imagem digital possuem muitos pontos iguais, isto é, são redundantes. A função do codificador de fonte é retirar essa redundância natural do sinal usando técnicas de compressão dados, mas sem perda de informação.

O codificador de canal introduz uma redundância controlada (ex: bits de paridade) na mensagem. Essa redundância será usada no receptor para tentar detectar e corrigir possíveis erros no sinal recebido. 
A informação digital, em geral, não pode ser transmitida diretamente através do canal. Antes, porém, deve ser convertida em formas de ondas que podem trafegar pelo canal. Nessa operação, os bits podem ser inicialmente agrupados para formar palavras (símbolos) com 2, 3, ou mais bits com uma duração $T$ segundos. Cada palavra digital é então mapeada em uma forma de onda correspondente. Essa é a função do modulador digital.

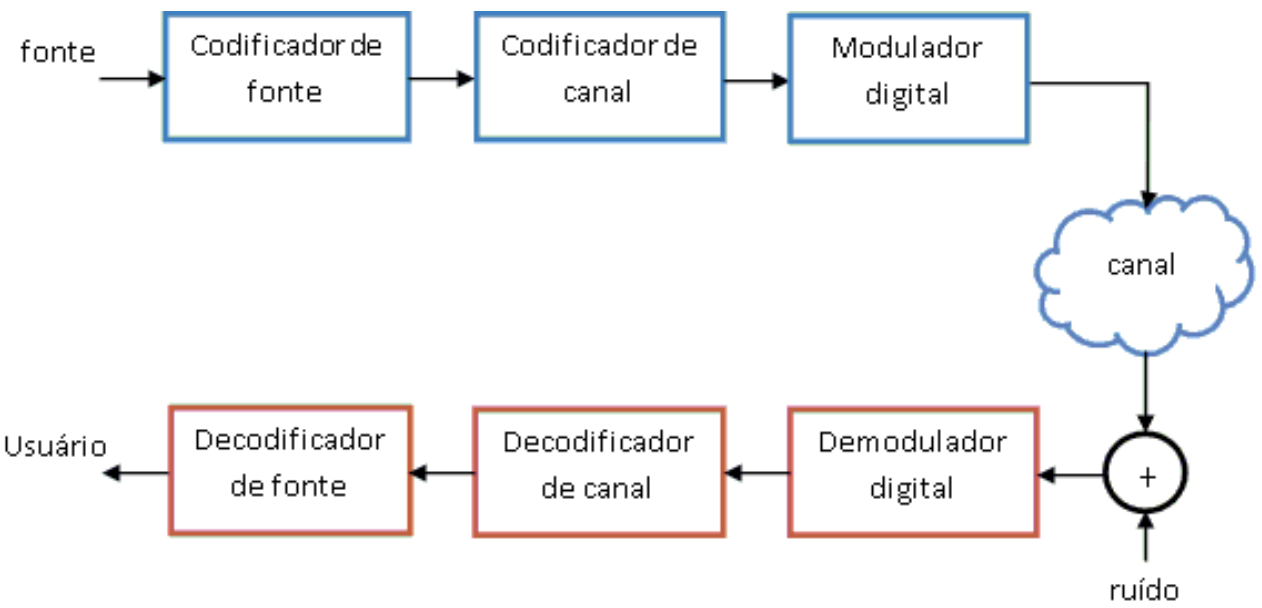

Figura 1. Diagrama de blocos de um sistema de comunicação digital.

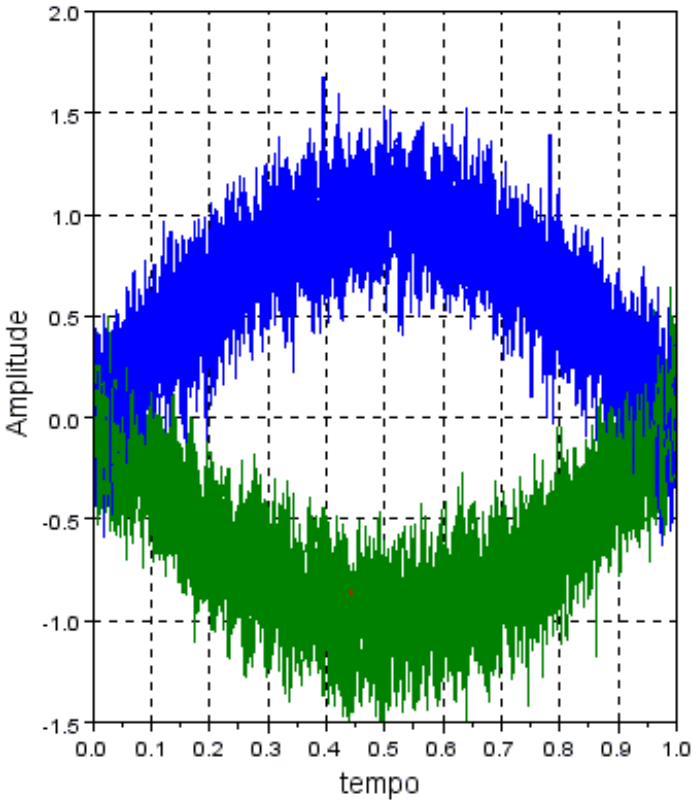

(a)

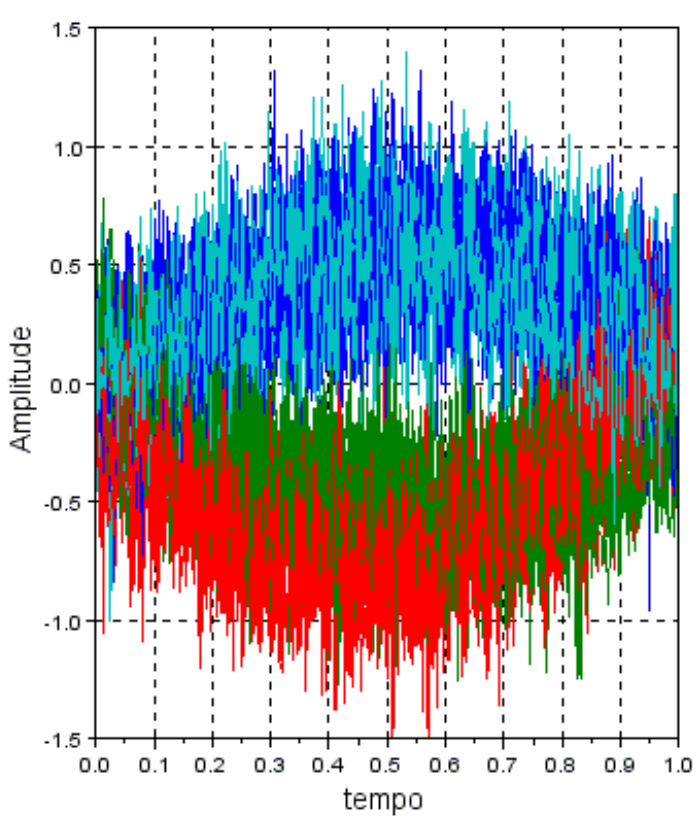

(b)

Figura 2. Diagrama de olho: (a) olho aberto, (b) olho fechado.

No lado do receptor são realizadas as operações inversas daquelas realizadas pelo transmissor. A diferença ou uma função da diferença entre o sinal reconstruído no receptor e o sinal transmitido é uma medida da quantidade da distorção introduzida pelo sistema de comunicação digital. Se a distorção for grande, a taxa de erros será elevada e algum tipo de estratégia deverá ser usada para realizar a correção dos dados que chegam ao receptor. A Figura 
2 ilustra dois diagramas de olho, no primeiro o olho está aberto e no segundo o olho está fechado. O segundo diagrama de olho requer o uso de um equalizado para que a taxa de erros não seja elevada.

\section{NOTAÇÃO MATEMÁTICA}

Neste artigo são usadas a notação matemática e definições indicadas a seguir. Letras minúsculas em itálico indicam "símbolos" unidimensionais: o sinal transmitido será denotado por $a[k]$; o sinal recebido será denotado por $r[k]$, onde $k$ é um índice temporal. Esses sinais podem ser reais ou complexos, sendo a unidade $j \equiv \sqrt{-1}$ imaginária.

Vetores (matrizes com apenas uma coluna e várias linhas) são indicados por letras minúsculas em negrito: $\mathbf{h}[k]=\left[h_{0}[k], h_{1}[k], \ldots, h_{L}[k]\right]^{T}$ indica um canal de comunicação no instante $k, r[k]$ é um vetor de dados recebidos, a[k] é um vetor de dados transmitidos e [.] ${ }^{T}$ indica a operação de transposição. Os coeficientes do equalizador são agrupados em um vetor complexo $\mathbf{w}[k]$.

Uma matriz (seja ela quadrada ou retangular) é representada por uma letra maiúscula em negrito, por exemplo: $\mathbf{H}$ representa a matriz de convolução do canal de comunicação.

As operações matemáticas possíveis com esses vetores e matrizes são indicadas por: * (conjugação complexa de um número, vetor ou matriz), $\mathbf{M}^{H}$ (Hermitiana de uma matriz), $\mathbf{M}^{-1}$ (inversão de uma matriz quadrada), $\mathbf{M}^{\dagger}$ (pseudo-inversa de uma matriz não quadrada) e $E\{$. $\}$ sendo a operação de esperança matemática.

Dessa forma, o sinal recebido no receptor pode ser genericamente expresso por:

$$
r(t)=\sum_{k=-\infty}^{k=+\infty} a(t) h(t-k T)+n(t)
$$

sendo $T$ o período de símbolo, $n(t)$ o ruído guassiano aditivo, $a(t)$ é o sinal transmitido e $h(t)$ representa a resposta ao impulso do canal que inclui os filtros de transmissão e recepção, o canal físico e a não sincronização temporal entre transmissor e receptor. Considerando-se o sinal digital sendo amostrado à taxa de símbolo e um canal de comprimento finito, isto é, um canal do tipo FIR (finite impulse response) pode-se reescrever a equação 1 como

$$
r[k]=\sum_{m=0}^{m=M} a[k-m] h_{m}[k]+n[k]
$$

\section{FUNDAMENTOS SOBRE O PROCESSAMENTO LARGAMENTE LINEAR}

Foi mostrado por Picinbono (1995) que em algumas situações a matriz de pseudocovariância, isto é, $\mathbf{C}=E\left\{\mathbf{x x}^{T}\right\}$ é não nula. Esse fato é particularmente verdadeiro quando é calculada a pseudocovariância do sinal resultante de uma constelação real (ex: BPSK, PAM, OQAM) transmitida por um canal complexo (Gerstacker et al., 2004). Nessa situação diz-se que o 
sinal é impróprio e o uso do processamento largamente linear é claramente superior ao processamento estritamente linear (Picinbono e Chevalier, 1995). Isso significa que o uso conjunto de $\mathbf{r}[k]$ e $\mathbf{r}^{*}[k]$ pode melhorar muito a estimativa do sinal transmitido que chega ao receptor. Para uma discussão mais detalhada sobre os aspectos teóricos do processamento largamente linear, o leitor pode consultar Ollila (2008) e Picinbono \& Bondon (1997).

Aplicando esses conceitos à equalização de um canal de comunicação o sinal e notação vetorial introduzida na seção anterior, o sinal estimado pode ser expresso por:

$$
\tilde{a}[k]=\mathbf{w}_{1}{ }^{H}[k] \mathbf{r}[k]+\mathbf{w}_{2}{ }^{H}[k] \mathbf{r}^{*}[k]
$$

Os coeficientes dos filtros $\mathbf{w}_{1}$ e $\mathbf{w}_{2}$ devem ser ajustados para acompanhar o canal de comunicação já que este é variante no tempo. Isso exige o uso de algum tipo de algoritmo adaptativo.

\section{CONCEITOS BÁSICOS SOBRE EQUALIZAÇÃO ADAPTATIVA}

Os algoritmos adaptativos podem ser classificados em dois grandes grupos: treinados e autodidatas (ou cegos). Nos algoritmos treinados uma sequência de treinamento está disponível no receptor. Essa sequência de treinamento é usada para ajustar periodicamente os coeficientes do equalizador. Na equalização autodidata não existe tal sequência de treinamento, mas apenas o conhecimento do comportamento estatístico do sinal que é transmitido (Proakis, 1995).

Os principais algoritmos adaptativos treinados são o LMS (Least Mean Square), LS (Least Square) e o RLS (Recursive Least Square). O algoritmo LMS é o que oferece menor custo computacional, mas tem uma covergência relativamente lenta que depende do maior ou menor espalhamento dos autovalores da matriz de correlação dos dados de entrada (Haykin, 1995).

Para o caso linear, o algoritmo LMS pode ser expresso por:

$$
\begin{aligned}
& y[k]=\mathbf{w}^{H}[k] \mathbf{r}[k] \\
& e[k]=d[k]-y[k] \\
& \mathbf{w}[k+1]=\mathbf{w}[k]+\mu e[k] \mathbf{r}^{*}[k]
\end{aligned}
$$

onde $0<\mu<<1$ é o passo de adaptação. Já o algoritmo LMS Normalizado pode ser expresso por:

$$
\begin{aligned}
& y[k]=\mathbf{w}^{H}[k] \mathbf{r}[k] \\
& e[k]=d[k]-y[k] \\
& \mathbf{w}[k+1]=\mathbf{w}[k]+\mu_{N} \frac{e[k] \mathbf{r}^{*}[k]}{\|\mathbf{r}[k]\|^{2}+\epsilon}
\end{aligned}
$$

(equação 5c)

sendo $\mu_{N}$ o passo normalizado (em geral próximo ao valor um) e $\varepsilon$ é uma constante pequena.

Os principais algoritmos autodidatas, incluindo os históricos, são: o algoritmo de decisão direta de Lucky (1966), algoritmo de Sato (1975), CMA (constant-modulus algorithm, Godard, 1980), LS-CMA, BGR (Benveniste-Goursat-Ruget) e "Stop-and-Go" (Picchi \& Prati, 1987). Desses algoritmos, o CMA é o mais difundido e, na sua versão básica, pode ser expresso por: 


$$
\begin{aligned}
& y[k]=\mathbf{w}^{H}[k] \mathbf{r}[k] \\
& e[k]=y[k]\left(|y[k]|^{2}-1\right) \\
& \mathbf{w}[k+1]=\mathbf{w}[k]+\mu e^{*}[k] \mathbf{r}[k]
\end{aligned}
$$

(equação 6c)

Neste artigo, são usadas as versões básicas dos algoritmos LMS e CMA nas simulações. O leitor interessado em informações adicionais sobre esses algoritmos pode consultar Haykin (1995) e Proakis (1995) ou Diniz (1997).

\section{EQUALIZADORES FRACIONALMENTE ESPAÇADOS}

Até agora foi considerado que a amostragem dos símbolos no receptor seria realizada à taxa de símbolo $T$, a mesma taxa com que os símbolos são gerados. Entretanto, nada impede que o receptor use uma taxa mais elevada. Isso pode levar a uma maior complexidade do receptor, mas também pode melhorar significativamente o desempenho de um equalizador (Gitlin, 1981; Ungerboeck, 1976).

Em geral, a nova taxa é uma fração da taxa $T$ original, tipicamente $T / 2$ (Johnson Jr. et al., 1998). Um equalizador operando a uma taxa $T / q$, sendo $q$ um valor inteiro maior que um, é chamado de equalizador fracionalmente espaçado (EFE). Este artigo é focado em equalizadores que usam taxa $T$ ou $T / 2$. Aparentemente, a idéia de aplicar o processamento largamente linear a equalizadores FE foi proposta inicialmente por Cacciapuoti et. al. (2006).

A Figura 3 ilustra o modelo de um sistema que usa a taxa $T / 2$. Nesse modelo, o canal é dividido em dois subcanais (coeficientes pares em um canal e coeficientes ímpares no outro subcanal) que recebem o mesmo sinal $a[k]$ transmitido à taxa $T$.

Uma vantagem importante de um equalizador $\mathrm{FE}$, relação a um equalizador que opera à taxa de símbolo é que o primeiro é menos sensível à sincronização do sinal recebido (Proakis, 1995). Outro ponto importante: sob algumas condições, o equalizador FE é capaz de compensar perfeitamente um canal sem ruído. Ou seja, a convolução canal-equalizador resulta um único impulso atrasado $\delta[k-N]$, sendo $N \geq 0$ um atraso (Johnson Jr. et al., 1998). Isso não é possível para um equalizador linear operando à taxa de símbolo.

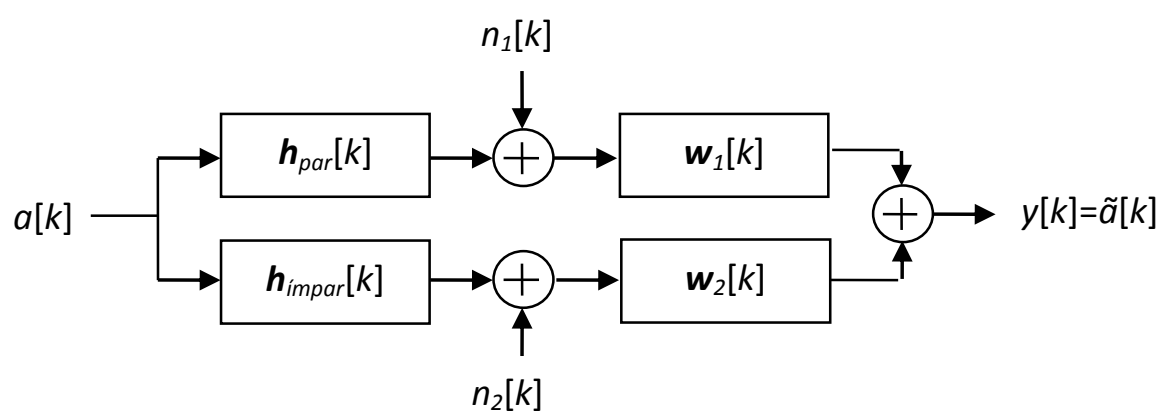

Figura 3. Modelo de sistema usando equalização FE (T/2).

\section{EQUALIZADORES FE LARGAMENTE LINEARES (FE-LL) ÓTIMOS}


A combinação do processamento largamente linear e de equalizadores FS pode levar a um desempenho de equalização superior ao uso de cada uma delas separadamente. Essa combinação será detalhada a seguir.

A combinação FS-LL "transforma" o canal de comunicação em quatro subcanais ( $\boldsymbol{h}_{\text {par, }}$, $\mathbf{h}_{\text {impar, }}, \mathbf{h}_{\mathrm{par}}{ }^{*}$ e $\mathbf{h}_{\text {impar }}{ }^{*}$ ), sendo por tanto necessário quatro filtros para estimação do sinal transmitido, como mostra a Figura 4. Essa estimação pode ser feita levando-se em conta o ruído (equalização MSE - mean square error) ou não (equalização ZF - zero forcing).

O equalizado ótimo, usando o critério MSE e usando a Figura 3 como referência, pode ser obtido seguindo-se o seguinte procedimento matemático (para não deixar a notação muito carregada foi omitido a dependência temporal indicada por " $[k]$ "):

$$
\begin{aligned}
& \mathbf{H}=\left[\begin{array}{ccccccc}
h_{0} & h_{2} & h_{4} & 0 & \ldots & 0 & 0 \\
0 & h_{0} & h_{4} & h_{4} & 0 & \ldots & 0 \\
0 & 0 & \ldots & \ldots & \ldots & \ldots & 0 \\
0 & \ldots & \ldots & h_{0} & h_{2} & h_{4} & 0 \\
0 & \ldots & 0 & 0 & h_{0} & h_{2} & h_{4} \\
h_{1} & h_{3} & h_{5} & 0 & \ldots & 0 & 0 \\
0 & h_{1} & h_{3} & h_{5} & 0 & \ldots & 0 \\
0 & 0 & \ldots & \ldots & \ldots & \ldots & 0 \\
0 & \ldots & \ldots & h_{1} & h_{3} & h_{5} & 0 \\
0 & \ldots & 0 & 0 & h_{1} & h_{3} & h_{5}
\end{array}\right] \\
& \mathbf{M}=\mathbf{H} \mathbf{H}^{H}+\eta \mathbf{I} \\
& \mathbf{v}=[0, \ldots 0,1,0, \ldots 0]^{T} \\
& \mathbf{M w}=\mathbf{H v} \\
& \mathbf{M}^{-1} \mathbf{h v}=\left[\begin{array}{c}
\mathbf{w}_{1} \\
\mathbf{w}_{2}
\end{array}\right]
\end{aligned}
$$

(equação 7a)

onde $\mathbf{H}$ é a matriz de convolução do canal à taxa $T / 2, \eta$ é a relação sinal-ruído, o elemento diferente de zero no vetor $\mathbf{v}$ indica o atraso de equalização, $h_{k}$ representa um coeficiente do canal e $\mathbf{w}_{1}$ e $\mathbf{w}_{2}$ são os filtros ótimos calculados. De forma semelhante e tendo por base a Figura 4, pode-se calcular os filtros ótimos de um equalizador FS-LL MSE. Para a equalização FE ZF (zero forcing), os cálculos de $\mathbf{w}_{1}$ e $\mathbf{w}_{2}$ são dados por:

$$
\begin{aligned}
\mathbf{H}_{z} & =\left[\begin{array}{ccccccccccc}
h_{0} & h_{1} & 0 & 0 & \ldots & 0 & 0 & 0 & 0 & 0 & 0 \\
h_{2} & h_{3} & h_{0} & h_{1} & 0 & \ldots & 0 & 0 & 0 & 0 & 0 \\
h_{4} & h_{5} & h_{2} & h_{3} & h_{0} & h_{1} & 0 & \ldots & \ldots & \ldots & 0 \\
0 & 0 & h_{4} & h_{5} & \ldots & h_{0} & h_{1} & 0 & \ldots & \ldots & 0 \\
0 & 0 & 0 & 0 & h_{4} & h_{5} & \ldots & h_{0} & h_{1} & 0 & 0 \\
0 & 0 & 0 & 0 & \ldots & 0 & h_{4} & h_{5} & \ldots & h_{0} & h_{1}
\end{array}\right] \\
\mathbf{v}_{z} & =[0,0, \ldots, 0,1,0, \ldots, 0]^{T} \\
\mathbf{w}_{z} & =\left(\mathbf{H}_{z}\right)^{+} \mathbf{v}_{z}
\end{aligned}
$$

(equação 8a)

(equação 8b)

(equação 8c) 


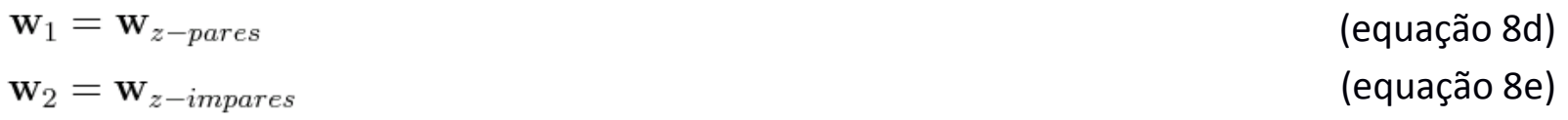

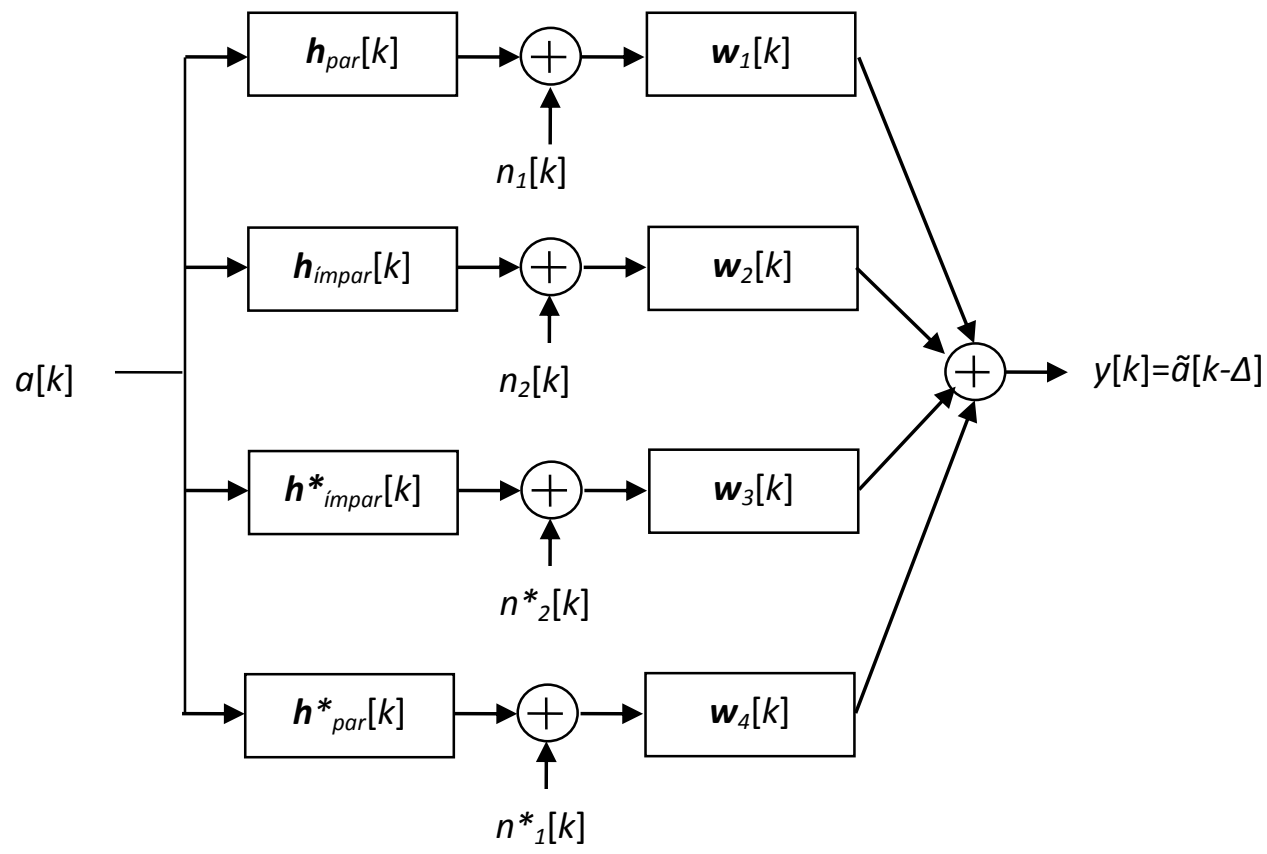

Figura 4. Modelo de sistema usando equalização FE (T/2) largamente linear.

\section{RESULTADOS DE SIMULAÇÃO}

Nesta seção são apresentados os resultados de simulação para os equalizadores ótimos (não treinados) e adaptativos (algoritmo LMS - treinado e CMA - autodidata) para equalização de canal comunicação digital. Em todas as simulações os dados são sequências binárias aleatórias de " +1 " e "-1" (constelação BPSK). O canal possui coeficientes complexos e o ruído é considerado gaussiano, de média nula e também complexo. Todas as simulações foram realizadas com o uso do software livre Scilab (Scilab, 2011).

\subsection{COMPARAÇÃO ENTRE EQUALIZAÇÃO ÓTIMA FE E FE-LL}

Nesta comparação são usados quatro equalizadores: FE MSE, FE ZF, FE-LL ZF e FE-LL MSE e o critério de desempenho é a taxa de erro de bit em função da relação sinal-ruído. Para obtenção destas curvas foram mediadas 500 realizações independentes com a transmissão de 40.000 símbolos em cada realização por um canal complexo de comprimento igual a seis amostras à taxa de símbolo e um atraso de equalização igual a quatro amostras. Esse atraso foi escolhido depois de alguns testes para maximizar o desempenho dos equalizadores. Os equalizadores têm apenas 6 coeficientes complexos para cada subcanal. Em cada uma das realizações foi gerado um canal com coeficientes aleatórios usando-se o código Scilab apresentado na Tabela 1.

Tabela 1. Código Scilab para geração dos canais

$\begin{array}{ll}\mathrm{h}=\operatorname{rand}\left(6,1, \text { 'normal' }^{\prime}\right)+\% \mathrm{i}^{*} \text { rand }\left(6,1, \text { 'normal'}^{\prime}\right) ; \quad / / \text { canal aleatório } \\ \mathrm{h}=\mathrm{h} / \underline{\operatorname{norm}}(\mathrm{h}) ; & / / \text { canal normalizado } \\ \mathrm{hc}=\operatorname{conj}(\mathrm{h}) ; & / / \text { canal conjugado }- \text { processamento LL } \\ \mathrm{h} 1=\mathrm{h}(1: 2: 6) ; & / / \text { coeficientes ímpares }\end{array}$


$\mathrm{h} 2=\mathrm{h}(2: 2: 6) ; \quad / /$ coeficientes pares

$\mathrm{h} 1 \mathrm{c}=\mathrm{hc}(1: 2: 6) ; \quad / /$ coeficientes ímpares - canal conjugado

$\mathrm{h} 2 \mathrm{c}=\mathrm{hc}(2: 2: 6) ; \quad / /$ coeficientes pares - canal conjugado

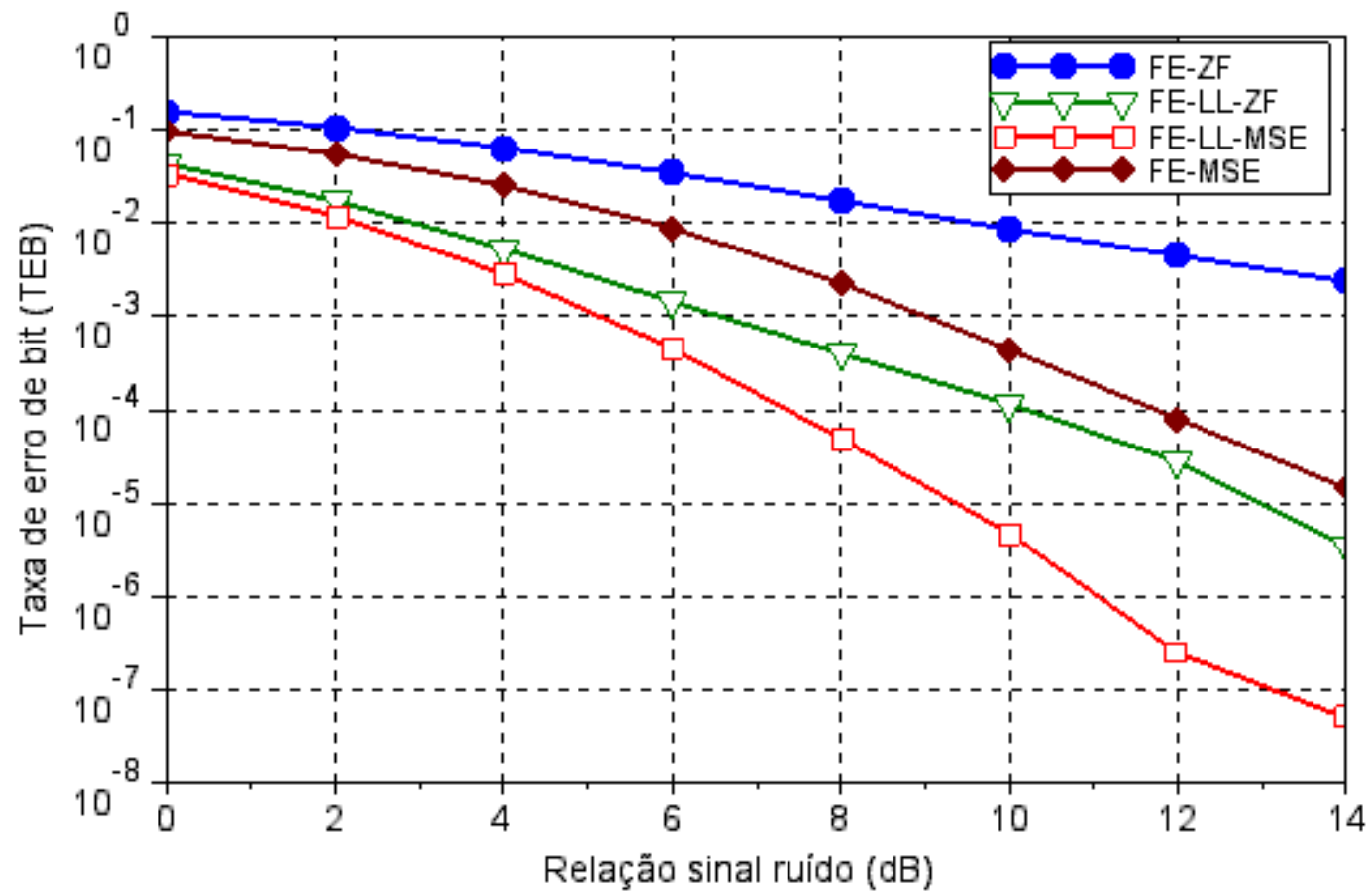

Figura 5. Comparação do desempenho de equalizadores ótimos.

Analisando as curvas da Figura 5, pode-se observar que o desempenho melhora com o aumento da relação sinal-ruído, mas que o apresenta melhor comportamento é o equalizador FELL MSE. Como já esperado, o pior desempenho fica com o equalizador FE-ZF.

\subsection{COMPARAÇÃO ENTRE EQUALIZADORES ADAPTATIVOS FE E FE-LL TREINADOS}

Nesta comparação são usados dois equalizadores adaptativos (FE e FE-LL) sendo usado o mesmo algoritmo o LMS normalizado $\left(\mu_{N}=0,35\right)$. Foram usados dois canais diferentes $\left(\mathbf{h}_{1 \_ \text {par }}=\right.$ $[0,303+0.719 j ; \quad-0,187-0,002 j ;-0,59+0,087 j]^{T}, \mathbf{h}_{1-i m p a r}=[-0,842+0,106 j ; \quad 0,24-0,132 j ;-$ $0,163-0,422 j]^{T}, \mathbf{h}_{2 \_ \text {par }}=[0,673-0,707 j ;-0,078-0,117 j ;-0,164+0,009 j]^{T}, \mathbf{h}_{2 \_ \text {impar }}=[0,219-$ $0,249 j ;-0,504-0,777 j ; 0,181-0,003 j]^{T}$ ) e uma relação sinal-ruído de $20 \mathrm{~dB}$.

Os equalizadores apresentam dez coeficientes complexos para equalizar cada subcanal e foram inicializados com um vetor nulo. $O$ atraso de equalização considerado foi de 4 amostras. Outros valores para o atraso de equalização poderiam ser usados, mas esse valor leva os equalizadores próximos ao desempenho ótimo.

No instante $k=750$ é realizada a mudança de um canal para outro para mostrar a estabilidade e tempo de recuperação dos equalizadores. Para os dois canais, o equalizador FE-LL apresentou um melhor desempenho. Uma explicação para essa diferença de desempenho é que os zeros dos subcanais $\mathbf{h}_{1 \_p a r}$ e $\mathbf{h}_{1 \_ \text {impar }}$ estão mais próximos que os zeros dos subcanais $\mathbf{h}_{2 \_p a r} \mathbf{e}$ 
$\mathbf{h}_{2 \_ \text {impar. }}$ Para os dois canais, o equalizador FE-LL apresentou uma melhor taxa de convergência e um menor erro médio quadrático após a convergência, como pode ser conferido na Figura 6.

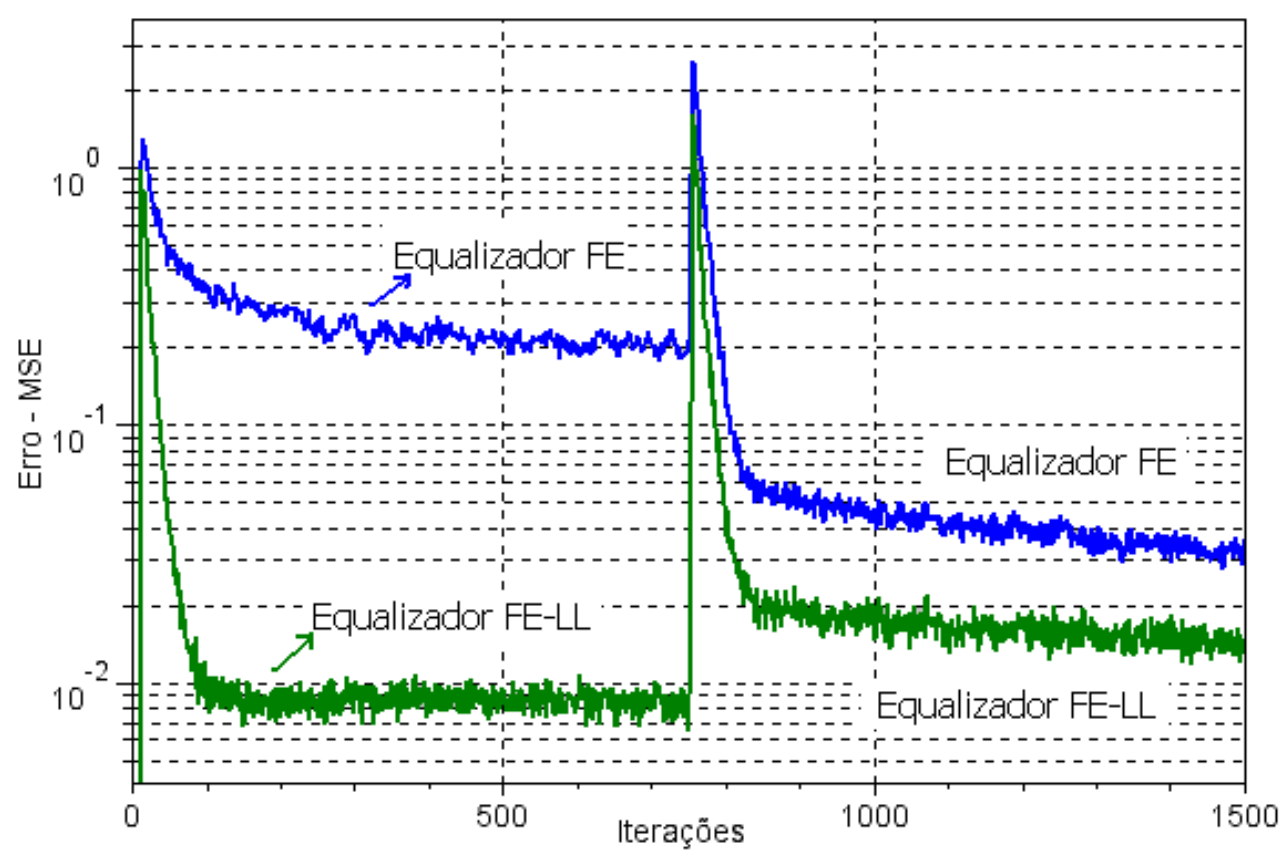

Figura 6. Comparação do desempenho dos equalizadores treinados.

\subsection{COMPARAÇÃO ENTRE EQUALIZADORES FE E FE-LL CEGOS}

Nesta comparação são usados os mesmos dois canais da seção anterior, mas com uma relação sinal-ruído de $30 \mathrm{~dB}$. Os equalizadores possuem dez coeficientes complexos para equalizar cada subcanal e foram inicializados com um vetor nulo, exceto na posição 4.

No instante $k=1000$ é realizada a mudança de um canal para outro para mostrar a estabilidade e tempo de recuperação dos equalizadores. Como pode ser conferido na Figura 7, para os dois canais o equalizador FE-LL cego apresentou um melhor desempenho, tanto na taxa de convergência quanto no erro médio quadrático após a convergência. Foram mediadas 500 realizações independentes para obtenção das curvas da Figura 7. Já a Figura 8 apresenta a IES residual após a equalização, obtida pela mediação de 50 realizações. A IES residual é calculada por:

$I E S_{d B}=10 \log _{10}\left(\frac{\sum_{k=0}^{M}\left|q_{k}\right|^{2}-\max _{k}\left|q_{k}\right|^{2}}{\max _{k}\left|q_{k}\right|^{2}}\right)$

(equação 8)

onde $q_{k}$ indica o $k$-ésimo termo da convolução entre canal e equalizador. A Equação 8 indica a habilidade do equalizador suprimir a IES, mas não revela o quanto o ruído será amplificado. Analisando-se as figuras 7 e 8, verifica-se que o equalzador FE-LL é que menos amplifica o ruído. Essa menor amplificação ocorre porque os coeficientes possuem maior grau de liberdade para realizar a mesma função do equalizador FE convencional. 


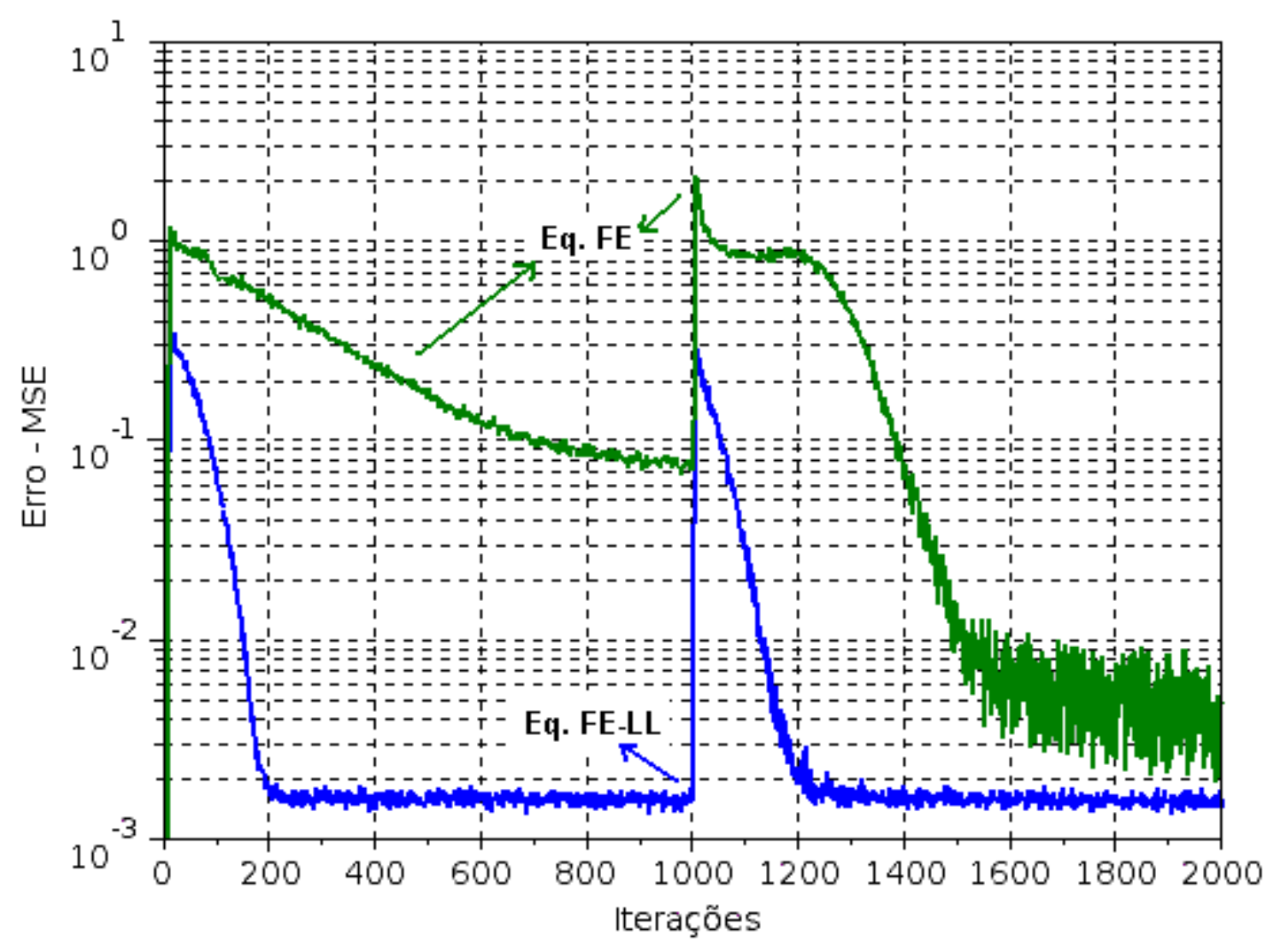

Figura 7. Comparação do desempenho dos equalizadores cegos.

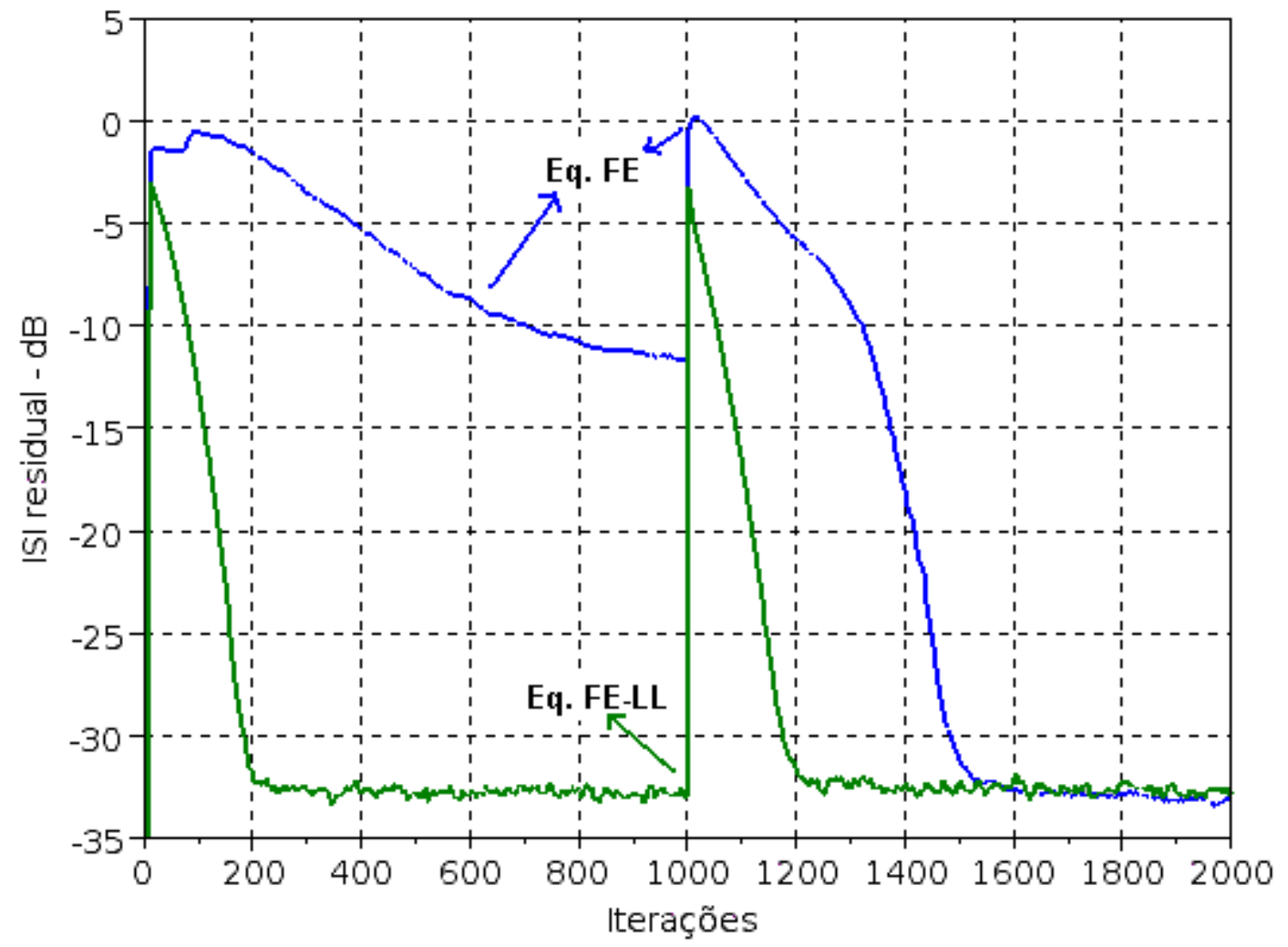

Figura 8. IES residual dos equalizadores cegos. 


\section{CONCLUSÕES}

Neste artigo foram apresentados os conceitos básicos sobre o processamento largamente linear, em especial aqueles aplicados à equalização do canal de comunicação. Foi analisado o uso do processamento largamente linear em conjunto com a técnica de superamostragem para a equalização de canais de comunicações em sistemas digitais. Verificou-se, através de simulações, que essa combinação apresenta um desempenho superior ao uso somente da técnica de superamostragem para equalização de canal em comunicações digitais. Essa estrutura pode ser implementada e testada em uma plataforma FPGA (Field-programmable gate array) para uma avaliação experimental com dados reais e não apenas simulação computacional.

\section{AGRADECIMENTOS}

Os autores agradecem ao Instituto Federal de Educação do Ceará (IFCE) pela bolsa PROAPP, à FUNCAP - Edital 007/2010, Programa Primeiros Projetos no. 0033-00115.01.00/10, e o laboratório GPICE (Grupo de Processamento de Imagens) pelo apoio material e financeiro para o desenvolvimento desta pesquisa.

\section{REFERÊNCIAS BIBLIOGRÁFICAS}

1. BENEVISTE A., GOURSAT, M. Blind Equalizers. IEEE Trans. Commun., v. 32, n. 8, p. 871-883, Aug. 1984.

2. CACCIAPUOTI, A. S.; GELLI, G.; PAURA, L.; VERDE, F. Widely-linear fractionally-spaced blind equalization of frequency-selective channels. In Proc. of 14th European Signal Processing Conference (EUSIPCO), Florence (Italy), Sept. 2006.

3. DINIZ, P. S. R. Adaptive Filtering: Algorithms and Practical Implementation. Kluwer Academic Publishers, Norwell, USA, 1997.

4. GITLIN, R. D. Fractionally spaced equalization: An improved digital transversal equalizer. Bell Syst. Tech. J., v. 60, p. 275-296, Feb. 1981.

5. GODARD, D. N. Self-Recovering Equalization and Carrier Tracking in Two-Dimensional Data Communication Systems. IEEE Trans. Commun., v. 28, p. 1867 - 1875, Nov. 1980.

6. HAYKIN, S. Adaptive Filter Theory, 3rd ed. Englewood Cliffs, NJ: Prentice-Hall, 1996.

7. LUCKY, R. W. Techniques for adaptive equalization of digital communication systems. Bell Syst. Tech. J., v. 45, p. 255-286, Feb. 1966.

8. LUGANNANI, R. Intersymbol interference and probability of error in digital systems. IEEE Transactions on Information Theory, v. 15, p. 682 - 688, Nov. 1969.

9. OLLILA, E. On the Circularity of a Complex Random Variable. IEEE Signal Processing Letters, vol. 15, Nov. 2008.

10. PICCHI G., PRATI, G. Blind Equalization and Carrier Recovery Using a 'stop-and-go' decisiondirected algorithm. IEEE Trans. Commun., v. 35, p. 877 - 887, Sep. 1987.

11. PICINBONO, B. e BONDON, P. Second-order statistics of complex signals. IEEE Trans. Signal Processing, vol. 45, pp. 411-420, fev. 1997.

12. PIMENTEL, C. J. L. Comunicação Digital. Rio de Janeiro. Editora Brasport, 2007. 
13. PROAKIS, J. G. Digital Communications, 3rd ed. New York: McGraw-Hill, 1995.

14. SALTZBERG, B.R. Intersymbol interference error bounds with application to ideal band limited signaling. IEEE Trans. Information Theory, v.14, p. 263-268, July, 1968.

15. SATO, Y. A Method of Self-Recovering Equalization for Multi-level Amplitude-Modulation Systems. IEEE Trans. Commun., v. 33, p. 679-682, Jun. 1975.

16. SCILAB. The Free Platform for Numerical Computation. Disponível em <http://www.scilab.org>. Acesso: 18 de dez. 2011.

17. UNGERBOECK, G. Fractional tap spacing equalizer and consequences for clock recovery in data modems. IEEE Trans. Commun., v. 24, n. 8, p. 856-864, Aug. 1976.

18. WIDROW, B.; M.E. HOFF, Jr. Adaptive switching circuits. IRE WESCON Conv. Rec., part 4, p. 96-104. Aug. 1960. 